\title{
Sustainable Mobility at a University Campus: Walking Preferences and the Use of Electric Minibus
}

\author{
Laura Eboli, Gabriella Mazzulla and Antonio Salandria \\ University of Calabria, Department of Civil Engineering \\ laura.eboli@unical.it,gabriella.mazzulla@unical.it,antonio.salandria@libero.it
}

\begin{abstract}
The most useful strategies to reduce traffic congestion and the consequences on the environment are linked to the improvement of the use of sustainable transport systems such as electric transit systems and of the pedestrian mobility. This study has the aim to investigate on the factors influencing the preferences of the users just between these two alternative modes: walking and moving by a transit system. We propose a study of the mobility inside a university campus sited in a wide suburban area. The main structures of the campus are located along a steel bridge 1.5 kilometres long. The mobility on the bridge is mainly a pedestrian mobility, but there is also a service offered by an electric minibus. Specifically, discrete choice models are proposed to establish the characteristics of the alternative modes and the attitudes of users mostly affecting their preferences. The models are based on the use of experimental data collected by a sample survey. Interesting results are obtained, suggesting that personal attitudes of the users and service quality aspects influence their preferences of moving.
\end{abstract}

Keywords: pedestrian mobility, logit models, service quality attributes, attitudinal characteristics

\section{Introduction}

Traffic congestion and delays continue to be a problem for both large and small cities, due to the excessive use of the private car. An important strategy to reduce the use of the private car is offering by public transport services characterized by high levels of quality, and by pedestrian mobility.

Supporting pedestrian mobility is a key factor in a sustainable urban development. Pedestrian mobility promoting is generally important at the urban scale, but also inside a large part of an urban area that is a university campus. There can be many reasons detracting people's attitude to walk, such as low accessibility, unsafe walking condition, uncomfortable density or unpleasant view, etc. [1]. One of the objective of the proposed study is just to understand the factors affecting the inclination to move by walking, and particularly the personal attitudes of people influencing the preference to walk. We investigate about these factors by analysing the preferences of the users between two different alternative modes inside a university campus: walking or moving by electric minibus. In this way, we have the possibility to investigate also on the minibus service quality factors influencing the choice between walking and minibus.

Specifically, we propose a study of the mobility inside a university campus sited in a wide suburban area where the main structures of the campus are connected along a steel bridge characterized by a length of about 1.5 kilometres. The mobility on the bridge is mainly a pedestrian mobility, but there is also a service offered by an electric minibus as alternative to the "on foot" mode. We investigate on the attributes affecting the users' choices between the 
two alternative transport modes, by proposing discrete choice models based on the utility of the users. The aim of the study is to understand if variables describing the quality of the two transport modes can influence users' preferences, and variables concerning personal attitudes of the users can affect the preferences of the users between a non motorized mode and a motorized mode to move inside the campus. Despite transport mode choice analysis usually involves other transport modes, especially private car, this study case is very peculiar because we deal with a particular situation of mobility inside a university campus happening on a bridge connecting all the structures of the campus, where only the two considered transport modes are available; on the bridge, also service cars and bicycles can circulate, but very few people use the latter. In addition, we believe that the results emerging from this study could be used also to define strategies for sustainable transportation which can be adopted inside pedestrian or traffic limited urban areas.

The paper is structured as follows: after this introduction, we propose a brief literature review concerning the factors mostly influencing the choice of walking, and the service quality attributes influencing public transport modes; in the following, we describe the experimental context, and specifically the mobility inside the campus, the survey conducted to collect the opinions of the users for analysing their preferences concerning the two analysed transport modes, and the sample characteristics; then, the models are presented: after a brief theoretical framework about the discrete choice models, and specifically Logit models; we show the results obtained from the calibration of four different specifications, and we discuss the main findings. Finally, we propose the main conclusions about the work.

\section{Literature review}

The choice of travel mode has been largely investigated in the transportation research field, and especially by using discrete choice modelling approach. Generally, studies have investigated on the choice between private transport modes and public transport modes or sustainable modes such as walking or bicycle. This work deals with a particular kind of choice between two sustainable transport modes, such as walking and electric minibus. So, the following literature is essentially about studies investigating the kinds of factors mostly affecting the choice of the users to move by walking, and very briefly the factors influencing the quality of public transport modes.

In a study of Bamberg et al., [2] about the kinds of factors affecting travel mode choice, the authors found that choice of travel mode is largely a reasoned decision, and this decision can be affected by interventions producing change in attitudes, subjective norms, and perceptions of behavioural control; the authors found also that past travel choice contributes to the prediction of later behaviour only if circumstances remain relatively stable.

In another study, Collins and Chambers [3] analyzed the relative importance and relationship between psychological and situational factors in predicting commuter transport mode choice. Regression analyses indicated support for the mediation, situational, and interaction hypotheses. It was concluded that to achieve a transport mode shift to public transport, public policy strategies should focus on individuals' transport-related environmental beliefs (personal control and environmental effect of cars) and situations (access to public transport at reduced cost).

More specifically about the choice of walking, in Kim et al., [4] a useful review of the factors influencing walking is reported. The authors state that the walking factors are divided into physical environmental elements and human subjective elements. The physical environmental elements are the ones for walking facilities, and the human subjective elements are ones that could be differently represented depending on individual preferences. Also Handy [5], who proposed a review of the methodologies employed in the land use-transportation research, found that the physical environment is an influence factor of walking. The same 
researcher conducted an extensive review of prior reviews and studies focusing on the effects of the built environment on walking [6].

Lee and Moudon [7] classified the walking influence elements into physical environmental elements, changes of direction, visual field and accessibility to use for path finding through arbitrary weights.

Economic factors (e.g., travel cost, income, expense, etc.) and demographic factors (such as gender and ethnicity) were demonstrated as important by Mahalavat et al., [8]. Travel time is also a significant factor affecting students' travel modes, as shown by Mahalavat et al., [8] and Ewing et al., [9].

The study of Parisi and Brett [10] has shown that distance, traffic, and crime are three key factors preventing students from walking/biking to school. Also Zhou et al., [11] found that factors such as distance, safety, climate, pathways, time, violence or crime affect children's walking or biking to go to school.

Concerning the analysis of the factors influencing the public transport modes, there are several studies based on the evaluation of bus service quality. The most recent examples are provided by Cirillo et al., [12]; dell'Olio et al., [13]; de Ona et al., [14]; Eboli and Mazzulla [15, 16, 17, 18]; Joewono and Kubota [19]; Nurul-Habib et al., [20]. In many of these studies the authors found that more qualitative attributes such as comfort, cleanliness, crowding or personnel friendliness have an influence in users' preferences. We want to specify that all these studies are based on the analysis of the users' preferences between different types of public transport services. According the authors' knowledge, there are no studies investigating on the factors influencing walking or a public transport mode based on the choice between "on foot" mode and minibus.

Thanks to the analysis of the literature, we decided to investigate on both environmental factors, such as the walking path and other characteristics of the travel modes, and human factors, such as personal attitudes of the users, as we will describe in the following of the paper.

\section{Experimental Context}

\subsection{Mobility inside the university campus}

The area used as test site is the campus of the University of Calabria. The campus is sited in a hilly region of Rende, a city of the South of Italy, extending on 250 hectares. The predominant element of the architectural style is represented by a steel bridge on two levels 1,450 metres long. On each of the two sides of the bridge there are the structures of the campus designed to didactic and service activities (such as the departments and lecture hall). In the less close to the bridge areas, the residential services are located (Figure 1; Figure 2). The university arose in 1972 and offered six faculties at the time of the survey: Economics; Engineering; Pharmacy; Arts; Mathematical, Physical, and Natural Science; Politics. There are also some inter-faculty courses. Today, the campus is attended by about 35,000 students and 2,000 workers.

The campus area is served by a road system inside the campus connecting the main structures of the campus. This road system is linked to the road system outside the campus. Along the road system inside the campus, some parking areas serving the private cars are placed. 


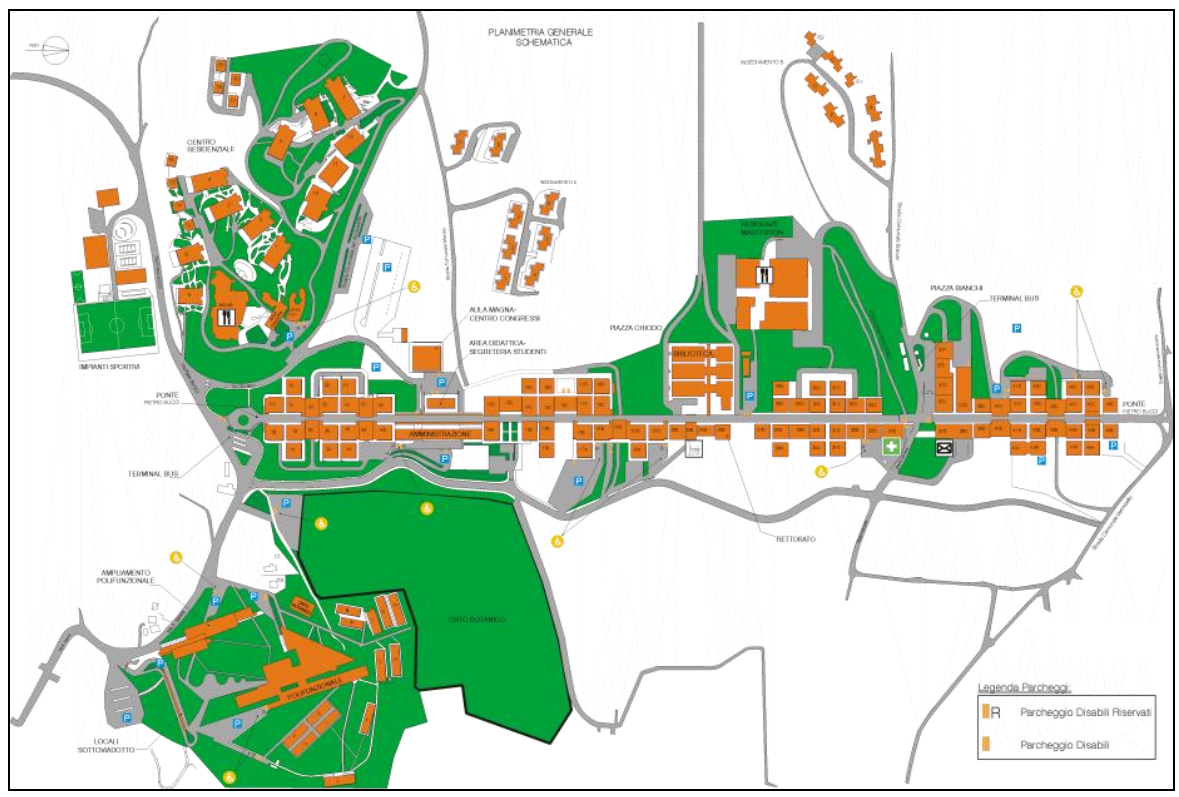

Figure 1. Map of the campus

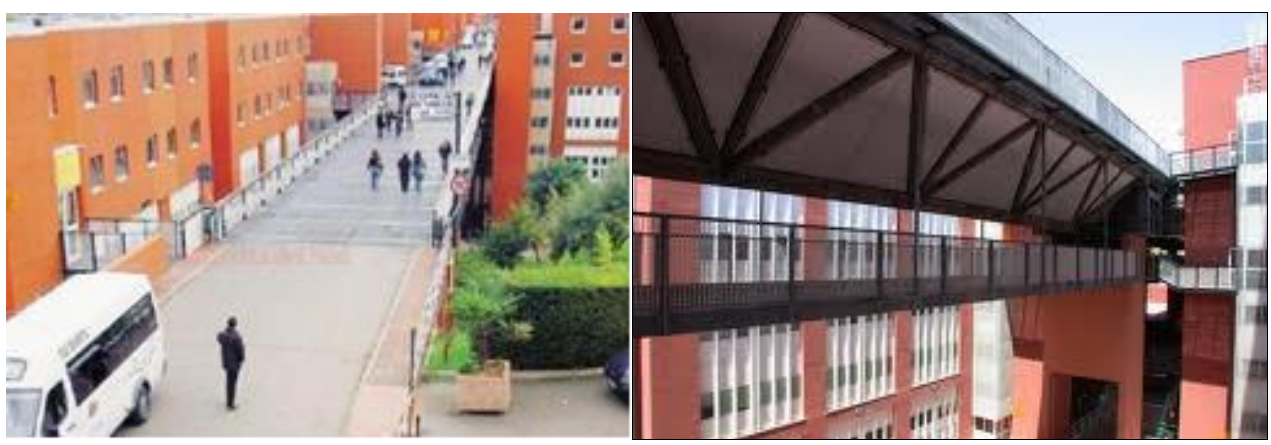

Figure 2. The bridge

The area is also served by bus lines connecting the university campus with the urban area, but the supplied services have a lower quality level, so a considerable part of students reach the campus by car. Specifically, from a survey conducted during 2005, we estimated 34,000 persons reaching the campus every day: there are about 19,500 passengers of 15,000 cars, about 4,500 pedestrians, about 1,200 passengers of urban buses and 8,800 of extra-urban buses [21]. So, in average, access mobility is oriented towards car mode (57\%), but a relevant part of the access trips are made by walking $(13 \%)$ or by bus $(30 \%)$. These percentages are different among the students attending the various faculties, due to the place where the faculty structures are located as regards the terminal bus. In fact, as an example, Engineering students prevalently reach the campus by car (more than twice compared to the bus mode) because Engineering faculty is located at the end of the bridge, far away from the terminal bus; on the contrary, Economics students reach fairly the campus by car and bus, probably because Economics faculty is located at the beginning of the bridge, near the terminal bus.

From the same survey, the interviewed male students prevalently move by car (59\% against $30 \%$ of female), whereas females move prevalently by bus (58\% against $35 \%$ of male). Also 
people moving on foot are differently distributed between males and females (6\% against $12 \%$, respectively).

Some differences emerge also by analyzing the class of income of the interviewed students. In fact, the students who use the private car for accessing the campus belong prevalently to a high class of family income (59\%), while $51 \%$ of the bus riders belong to the lower class of family income. In this case, people walking for reaching the campus are equally distributed among the different class of family income.

Finally, the incidence of age on access transport mode showed, as expected, that older students (aged more than 22) choose car alternative (more than 60\%), whereas younger (aged between 18 and 22) are inclined towards the use of bus (52\%), likely because they have not a drive license.

Every day, thousands of people move on the bridge by walking, especially the students reaching the campus by public transport. The mobility on the bridge is also characterized by the presence of an electric minibus serving the main structures of the campus, and assuring the people to reach the different faculties of the university. The minibus line path is characterized by eight stops; the terminals are sited at the beginning of the bridge near the main terminal bus of the campus, and at the end of the bridge, near the faculty of the Engineering, sited at the end of the campus. There is only one minibus running on the bridge; the time to go from the terminal at the beginning of the bridge to the terminal at the end of the bridge, and to return at the beginning of the bridge is about 20 minutes; therefore, the frequency of the minibus is about three runs per hour. The most loaded runs are characterized by about 35 users on board. Also people move on the bridge by the minibus are students reaching the campus by public transport, and not by private car.

\subsection{Survey}

The sample survey aimed to the analysis of users' preferences between walking and taking the minibus involved a sample of 100 students attending the university campus, and was conducted in the month of May 2011. People were contacted while they were walking on the bridge connecting the various departments, or while they were waiting the minibus at the various bus stops; so, we adopted a simple random sampling. We have to specify that people walking on the bridge or taking the minibus essentially represent the students who reaching the campus by the public transport services or by foot; about 14,500 students $(4,500$ pedestrians and 10,000 passengers of urban and extra-urban buses) reach the campus every day to make different activities. So, we can conclude that the sample rate is equal to about $0.7 \%$. Users were asked to answer a face-to-face questionnaire composed of four sections. The first section aimed to collect information concerning socio-economic characteristics of the users, such as gender, age, faculty, family income. Through the second section, information regarding the users' trips inside the university campus were collected (e.g., origin and destination of the trip inside the campus, purpose of the trip, transport mode used inside the campus). The third section is about the characteristics of the two alternative transport modes available for the users to move along the bridge: on foot or by minibus. Users provided their opinions about the following characteristics relating the mode "on foot": travel time, crowding level on the path, quality of the path in terms of slope and protection from the rain, quality of the path facilities in terms of lighting, parks, and rest areas. On the other hand, users provided opinions about analogous characteristics relating the minibus: travel time (access and egress, waiting, and on board time), crowding level on board, comfort on board in terms of cleanliness, seats, and air conditioning, quality level of the stop facilities in terms of lighting, shelter, benches, and dispenser (Table 1). 
Table 1. Section 3 of the questionnaire

\begin{tabular}{|c|c|c|}
\hline Transport mode & Characteristic & Responses \\
\hline \multirow{4}{*}{ Walking } & Travel time & $\begin{array}{l}\text { time expressed in } \\
\text { minutes }\end{array}$ \\
\hline & Crowding level on the path & $\begin{array}{l}1 \text { (low), } 2 \text { (medium), } 3 \\
\text { (high) }\end{array}$ \\
\hline & $\begin{array}{l}\text { Quality of the path in terms of slope and } \\
\text { protection from the rain }\end{array}$ & $\begin{array}{l}1 \text { (low), } 2 \text { (medium), } 3 \\
\text { (high) }\end{array}$ \\
\hline & $\begin{array}{l}\text { Quality of the path facilities (lighting, parks, and } \\
\text { rest areas) }\end{array}$ & $\begin{array}{l}1 \text { (low), } 2 \text { (medium), } 3 \\
\text { (high) }\end{array}$ \\
\hline \multirow{8}{*}{ Minibus } & Total travel time & $\begin{array}{l}\text { time expressed in } \\
\text { minutes }\end{array}$ \\
\hline & Time to the minibus stop & $\begin{array}{l}\text { time expressed in } \\
\text { minutes }\end{array}$ \\
\hline & Waiting time & $\begin{array}{l}\text { time expressed in } \\
\text { minutes }\end{array}$ \\
\hline & Time on board & $\begin{array}{l}\text { time expressed in } \\
\text { minutes }\end{array}$ \\
\hline & Time from the stop to the final destination & $\begin{array}{l}\text { time expressed in } \\
\text { minutes }\end{array}$ \\
\hline & Crowding level on board & $\begin{array}{l}1 \text { (low), } 2 \text { (medium), } 3 \\
\text { (high) }\end{array}$ \\
\hline & $\begin{array}{l}\text { Comfort on board (cleanliness, seats, and air } \\
\text { conditioning) }\end{array}$ & $\begin{array}{l}1 \text { (low), } 2 \text { (medium), } 3 \\
\text { (high) }\end{array}$ \\
\hline & $\begin{array}{l}\text { Quality of the stop facilities (lighting, shelter, } \\
\text { benches, dispenser) }\end{array}$ & $\begin{array}{l}1 \text { (low), } 2 \text { (medium), } 3 \\
\text { (high) }\end{array}$ \\
\hline
\end{tabular}

The last section aimed to collect information about some attitudes of the users: users had to answer about their pleasure of walking, patience, nuisance for confusion, laziness, and punctuality, according to the verbal scale shown in Table 2.

Table 2. Section 4 of the questionnaire

\begin{tabular}{|l|l|}
\hline Attitude & Responses \\
\hline Walking Pleasure & 1 (for nothing), 2 (little), 3 (enough), 4 (a lot) \\
\hline Patience & 1 (for nothing), 2 (little), 3 (enough), 4 (a lot) \\
\hline Nuisance for confusion & 1 (for nothing), 2 (little), 3 (enough), 4 (a lot) \\
\hline Laziness & 1 (for nothing), 2 (little), 3 (enough), 4 (a lot) \\
\hline Punctuality & 1 (for nothing), 2 (little), 3 (enough), 4 (a lot) \\
\hline
\end{tabular}

The selection of these five kinds of attitudes arises from a deep thinking of the authors about the reasons that can incite a user to decide to walk on the bridge or to wait for the minibus and take it, and also from their personal experience as users of the two analysed transport modes. With the term "walking pleasure" we intend the attitude of the users to move by walking and 
we expect that a user who likes walking is more oriented to choose to walk on the campus bridge for reaching his/her final destination. We think that the "patience" of a user could affect his/her capacity to wait for the minibus rather than walking on the bridge when he/she arrives at the campus, as well as the "nuisance for confusion" could incite a user to decide to walk on the bridge rather than take the minibus where could be a situation of overcrowding. At the same time the "laziness" could affect the attitude of a user to walk and therefore to incite him/her to easily wait the minibus. Finally, the "punctuality" could incite a user to walk on the bridge when he/she arrives at the campus rather than waiting for the minibus, risking to be late in attending lesson or making other activities.

\subsection{Sample statistics}

The sample is almost equally spread between males and females, and mostly composed of students aged between 23 and 25 and belonging to a low class of family income (1,000-2,000 Euros); the sample is rather proportionally distributed among the faculties of the university (table 1), according to the number of the registered students. In fact, the mostly attended faculties are Engineering (about $25 \%$ of the total students), Economics (about 24\%), and Arts (about 24\%); the other faculties are less attended: Pharmacy (about 12\%), (Mathematical, Physical, and Natural Science (about 7\%), Politics (about 6\%), and Inter-faculty (about 2\%).

Table 3 also shows the attitudinal characteristics of the users. Almost $80 \%$ of users state to be punctual; $70 \%$ of the sample likes walking enough or a lot, and almost $70 \%$ states to be not lazy; almost $60 \%$ of users have patience, and more than half of the sample doesn't feel nuisance for confusion.

Table 3. Socio-economic and attitudinal characteristics of the sample

\begin{tabular}{|c|c|}
\hline Characteristics & Statistics \\
\hline 1.Gender & Male $(48.0 \%)$, female $(52.0 \%)$ \\
\hline 2.Age & $20-22(30.0 \%), 23-25(50.0 \%), 26-29(20.0 \%)$ \\
\hline 3.Faculty & $\begin{array}{l}\text { Economics }(20.0 \%) \text {, Engineering (25.0\%), Pharmacy }(11.0 \%) \text {, Arts } \\
\text { (21.0\%), Mathematical, Physical, and Natural Science }(16.0 \%) \text {, } \\
\text { Politics (1.0\%), Inter-faculty }(6.0 \%)\end{array}$ \\
\hline 4.Income level & $\begin{array}{l}<=1,000(13.0 \%), 1,001-2,000(48.0 \%), 2,001-3,000(31.0 \%), \\
3,001-4,000(7.0 \%),>4,000 \text { Euros }(1.0 \%)\end{array}$ \\
\hline 5.Family components & $3(13.0 \%), 4(48.0 \%), 5(31.0 \%), 6(7.0 \%),>6(1.0 \%)$ \\
\hline 6.Walking pleasure & For nothing (11.0\%), little (19.0\%), enough (48.0\%), a lot (22.0\%) \\
\hline 7.Patience & For nothing (16.0\%), little (25.0\%), enough (47.0\%), a lot (12.0\%) \\
\hline 8.Nuisance for confusion & For nothing (14.0\%), little (42.0\%), enough (23.0\%), a lot (21.0\%) \\
\hline 9.Laziness & For nothing $(34.0 \%)$, little (35.0\%), enough $(26.0 \%)$, a lot $(5.0 \%)$ \\
\hline 10.Punctuality & For nothing $(9.0 \%)$, little $(12.0 \%)$, enough $(59.0 \%)$, a lot $(20.0 \%)$ \\
\hline
\end{tabular}

Table 4 provides information about the characteristics of the trips made by the users inside the university campus at the moment of the interview. The main purpose of the trip at the origin is the arrival of the user to the bus terminal by an urban or extra-urban bus, while the purpose at destination is to attend a lesson. The sample is almost equally spread between people making the trip on foot and people taking the minibus. We asked the users also for the transport mode usually adopted inside the campus: $33 \%$ of users usually move on foot, while $67 \%$ take the minibus. The average travel time on foot is about 17 minutes, while by minibus about 15 minutes. People wait at the stop about 5 minutes, while the time on board is about 8 minutes. People expressed their opinions about the quality of the walking path and the quality of the minibus service. According to the users, the level of crowding on the bridge is low $(52.0 \%)$ or 
medium (42.0\%), while the opinions about the quality level of the path, in terms of slope, protection from the rain, etc., are more heterogeneous ("medium" for $43 \%$ of users, "high" for $34 \%$, and "low" for $23 \%$ ). Finally, regarding the quality of the path facilities, they mostly expressed a medium level (52\%) and a low level (35\%); only $13 \%$ of users consider the path facilities characterized by a high level of quality.

Table 4. Trip characteristics

\begin{tabular}{|c|c|}
\hline Characteristics & Statistics \\
\hline 1.Purpose of the trip at the origin & $\begin{array}{l}\text { Arrive to the bus terminal }(100.0 \%) \text {, work }(0.0 \%) \text {, lesson } \\
(0.0 \%) \text {, studying }(0.0 \%) \text {, practice disposing }(0.0 \%) \text {, leisure } \\
(0.0 \%)\end{array}$ \\
\hline $\begin{array}{l}\text { 2.Purpose of the trip at the } \\
\text { destination }\end{array}$ & $\begin{array}{l}\text { Departure from the bus terminal }(0.0 \%) \text {, work }(0.0 \%) \text {, lesson } \\
(99.0 \%) \text {, studying }(0.0 \%) \text {, practice disposing }(1.0 \%) \text {, leisure } \\
(0.0 \%)\end{array}$ \\
\hline 3. Transport mode of the trip & By foot $(49.0 \%)$, minibus $(51.0 \%)$ \\
\hline 4. Usual transport mode & By foot $(33.0 \%)$, minibus $(67.0 \%)$ \\
\hline 5. Average travel time by foot & 17.13 minutes \\
\hline 6.Crowding on the on foot path & Low $(52.0 \%)$, medium $(42.0 \%)$, high $(6.0 \%)$ \\
\hline $\begin{array}{l}\text { 7. Quality level of the path (slope, } \\
\text { protection from the rain, etc.) }\end{array}$ & Low $(23.0 \%)$, medium $(43.0 \%)$, high $(34.0 \%)$ \\
\hline $\begin{array}{l}\text { 8. Quality level of the path } \\
\text { facilities (lighting, parks, rest } \\
\text { areas, etc.) }\end{array}$ & Low $(35.0 \%)$, medium $(52.0 \%)$, high $(13.0 \%)$ \\
\hline 7. Average travel times by minibus & $\begin{array}{l}\text { Total travel time }(14.46 \mathrm{~min}) \text {, time from the origin to the } \\
\text { minibus stop }(0.63 \mathrm{~min}) \text {, waiting time at stop }(4.59 \mathrm{~min}) \text {, on } \\
\text { board time }(7.67 \mathrm{~min}) \text {, time from the stop to the final } \\
\text { destination }(1.54 \mathrm{~min})\end{array}$ \\
\hline 9.Crowding on the minibus & Low $(3.0 \%)$, medium $(44.0 \%)$, high $(54.0 \%)$ \\
\hline $\begin{array}{l}\text { 10.Comfort on minibus } \\
\text { (cleanliness, seats, air } \\
\text { conditioning, etc.) }\end{array}$ & Low $(34.0 \%)$, medium $(52.0 \%)$, high $(14.0 \%)$ \\
\hline $\begin{array}{l}\text { 11. Quality level of the stop } \\
\text { facilities (lighting, shelter, } \\
\text { benches, dispenser, etc.) }\end{array}$ & Low $(54.0 \%)$, medium $(43.0 \%)$, high $(3.0 \%)$ \\
\hline
\end{tabular}

Concerning the minibus service, the major part of users stated that the level crowding on minibus is high $(54 \%)$ or medium (44\%). For $52 \%$ of users the level of comfort on bus (in terms of cleanliness, etc.) is medium, and low for $34 \%$ of users. Finally, the quality level of the minibus stop facilities is considered as low by more than half of the users, and medium by $34 \%$ of them.

\section{Models}

The characteristics described by the interviewed users concerning their personal attitudes and opinions about the two transport modes available for moving inside the campus were used for calibrating some logit models, useful for establishing the importance of the variables on the choice between the two alternative transport modes: on foot and by minibus. In the following, we present a brief theoretical framework about the logit models adopted for analyzing the data, and the results from the calibration of the models. 


\subsection{Theoretical framework}

Logit models are the better-known discrete choice models. These models are based on the Random Utility Theory (RUT), and on the hypothesis that the errors in the utility function are distributed according to the type I extreme-value (EV1) distribution.

Multinomial Logit (MNL) is the model with the simplest structure inside the Logit family. There are three fundamental hypotheses that underlie the MNL formulation. The first one is that the random components of the alternative utilities are independent and identically distributed (IID). The second one is that the MNL model maintains homogeneity in responsiveness to attributes of alternatives across individuals. Finally, the third hypothesis is that the error variance-covariance structure of the alternatives is identical across individuals [22].

To estimate heterogeneity in individual taste, mixed logit (ML) formulation should be adopted [23]. Supposed that the decision maker faces a choice among $J$ alternatives, the utility of person ${ }^{n}$ from alternative $j$ is specified as:

$U_{n j}=\beta_{n} x_{n j}+\varepsilon_{n j}$

where $x_{n j}$ are observed variables that researcher obtains from the decision maker, $\beta_{n}$ is a vector of coefficients of these variables for person $n$ representing that person's taste, and $\varepsilon_{n j}$ is an unobserved random term that is independent and identically distributed (IID) extreme value, independent of $\beta_{n}$ and $x_{n j}$. The coefficients among the population vary over decision maker with density $f(\beta)$ which is the function of the parameter $\theta$ that for example represent the mean and standard deviation of the $\beta$ 's in the population. The choice probability cannot be analytically calculated; therefore the exact maximum likelihood estimation is not possible. Instead, the probability is usually approximated through simulation [22, 24]. In these models the random parameters can have different functional form, such as normal, triangular, uniform and log-normal.

\subsection{Model specification and results}

We calibrated four different specifications of logit models: two MNL models, and two ML models with a normal distribution of the parameters (Table 5). We decided to estimate two models (MNL1 and ML1) for establishing the influence of the characteristics of the transport modes (travel times, comfort, crowding) on the choice between the two alternative modes. The other two models (MNL2 and ML2) have the objective to investigate on the influence of the attitudes of the users (walking pleasure, patience, and laziness). We decided to consider two different sets of models with different explanatory variables, in order to better investigate the two kinds of characteristics involved in the survey (quality aspects of the two transport modes, and attitudes of the users). Specifically, in the first two models (MNL1 and ML1), the utility of the "on foot" alternative contains the variables concerning age and travel time on foot, while all the other variables are in the utility of the minibus alternative. In the last two models, the utility of the "on foot" alternative contains all the attitudinal variables and travel time on foot, while the utility of the minibus alternative contains only the travel and waiting time on minibus.

The variables concerning the travel times are expressed in minutes, while the other variables are cardinal and expressed according the values shown in Table 3 and Table 4. Specifically, in each of the ML models, only one random parameter distributed with a normal distribution was considered. The random parameters concern the variable linked to the comfort on minibus for the ML1 model, and the variable regarding the walking pleasure for the ML2 model. All the other parameters are considered as fixed. Some ML models were specified and calibrated in 
which the other attributes were considered random, while we decided to report only the models characterized by the best results.

Some measures of overall model fit were effected. The Rho squared and Rho squared corrected statistics of the ML models have a value superior to the MNL model. The final values of Log-Likelihood of the models are comparable.

Table 5. Model results

\begin{tabular}{|c|c|c|c|c|c|}
\hline \multirow{2}{*}{ name } & \multirow{2}{*}{ variable } & \multicolumn{4}{|c|}{ estimated parameters (t-test) } \\
\hline & & MNL1 & ML1 & MNL2 & ML2 \\
\hline TFOOT & $\begin{array}{l}\text { On foot travel } \\
\text { time }\end{array}$ & $\begin{array}{l}-0.56 \\
(-2.8) \\
\end{array}$ & $\begin{array}{l}-2.12 \\
(-3.2) \\
\end{array}$ & $\begin{array}{l}-0.80 \\
(-3.9) \\
\end{array}$ & $\begin{array}{l}-3.05 \\
(-3.0) \\
\end{array}$ \\
\hline TBUS & $\begin{array}{l}\text { On board travel } \\
\text { time }\end{array}$ & $\begin{array}{l}-0.46 \\
(-1.6)\end{array}$ & $\begin{array}{l}-3.59 \\
(-3.8)\end{array}$ & $\begin{array}{l}-0.55 \\
(-2.0)\end{array}$ & $\begin{array}{l}-3.17 \\
(-2.0)\end{array}$ \\
\hline TWAIT & $\begin{array}{l}\text { Waiting time on } \\
\text { bus }\end{array}$ & $\begin{array}{l}-0.95 \\
(-2.3) \\
\end{array}$ & $\begin{array}{l}-2.12 \\
(-3.1) \\
\end{array}$ & $\begin{array}{l}-0.78 \\
(-2.2) \\
\end{array}$ & $\begin{array}{l}-2.05 \\
(-3.0)\end{array}$ \\
\hline AGE & $\begin{array}{l}\text { Age of the } \\
\text { student }\end{array}$ & $\begin{array}{l}-1.57 \\
(-1.3)\end{array}$ & $\begin{array}{l}-4.40 \\
(-1.5)\end{array}$ & & \\
\hline CROWDBUS & Crowding on bus & $\begin{array}{l}-1.43 \\
(-2.1)\end{array}$ & $\begin{array}{l}-4.12 \\
(-1.6)\end{array}$ & & \\
\hline COMFBUS (mean) & Comfort on bus & $1.82(2.1)$ & $1.82(2.1)$ & & \\
\hline $\begin{array}{l}\text { COMFBUS } \\
\text { (dev.st.) }\end{array}$ & & - & $7.5(2.1)$ & & \\
\hline WALK (mean) & Walking pleasure & & & $2.33(2.8)$ & $9.08(2.3)$ \\
\hline WALK (dev.st.) & & & & & $4.69(2.4)$ \\
\hline PAT & Patience & & & $\begin{array}{l}-1.02 \\
(-1.8)\end{array}$ & $\begin{array}{l}-4.01 \\
(-1.6)\end{array}$ \\
\hline LAZI & Laziness & & & $\begin{array}{l}-0.87 \\
(-1.4)\end{array}$ & $\begin{array}{l}-3.64 \\
(-1.3)\end{array}$ \\
\hline \multirow[t]{2}{*}{$\begin{array}{l}\text { Predicted } \\
\text { Probabilities }\end{array}$} & Minibus & $67 \%$ & $67 \%$ & $68 \%$ & $67 \%$ \\
\hline & On foot & $33 \%$ & $33 \%$ & $32 \%$ & $33 \%$ \\
\hline & $\%$ Right & $96 \%$ & $96 \%$ & $93 \%$ & $94 \%$ \\
\hline \multicolumn{2}{|c|}{ Final Log-Likelihood } & -14.97 & -11.96 & -14.63 & -13.11 \\
\hline \multicolumn{2}{|c|}{ Log-Likelihood with Zero coefficients } & -63.42 & -69.31 & -63.42 & -69.31 \\
\hline \multicolumn{2}{|c|}{ Likelihood Ratio test } & 96.90 & 114.70 & 97.58 & 112.40 \\
\hline \multicolumn{2}{|r|}{ Rho squared } & 0.76 & 0.83 & 0.77 & 0.81 \\
\hline \multicolumn{2}{|c|}{ Rho squared corrected } & 0.75 & 0.81 & 0.75 & 0.80 \\
\hline
\end{tabular}

Both mean and standard deviation of the random parameters assume a value statistically different from zero, at a 95\% level of significance. Also the fixed parameters are significant, except the variables concerning the age of users, patience, laziness, and time on minibus in the MNL1 model, and comfort on minibus in the ML1 model.

The parameters concerning the travel times of both the modes and the waiting time by minibus have a negative sign, as expected, because an increase of them causes a decrease of the utilities of the alternatives. Specifically, the waiting time has a weight, which is twice the time on board; generally, the users of the public transport modes perceive the time spending at the bus stop more than the time on board. The socioeconomic variable "Age" has also a negative sign, meaning that an increase of the age of users causes a decrease of the utility of the "on foot" alternative, so the younger students are more inclined to walking. The variable concerning the crowding on minibus has a negative sign, indicating that an increase of the level of crowding on bus causes a decrease of the utility of the minibus. While the sign of the variable regarding comfort on bus (in terms of cleanliness, seats, etc.) is positive, showing that an 
increase of the quality level of this attribute increases the probability to choose the minibus. Finally, we can observe the signs of the variables concerning the attitudes of the users, introduced in the "on foot" alternative mode. The positive sign of the variable regarding walking pleasure indicates that the probability of choosing to make the trip on foot increases for people who like walking. On the other hand, the increase of the levels of patience and laziness of the users have a negative impact on the choice of the "on foot" alternative, because patient and lazy users are more inclined to wait and use the minibus. The attribute linked to the walking pleasure has the highest influence on the choice.

\subsection{Discussion}

We obtained interesting results from the models. We found that personal attitude characteristics like walking pleasure, patience, and laziness can be considered as factors influencing the choice between the two transport modes, and specifically the attitude of the users to walk. The results from the models confirmed our hypotheses made during the selection of the attitudes included in the specification of the models. As we expected, a user who likes walking is more oriented to choose to walk on the campus bridge for reaching the final destination; however, this attitude shows a very heterogeneous distribution among the users. On the other hand, "patience" affect user capacity to wait for the minibus rather than walking on the bridge, as well as "laziness" incites user to wait the minibus.

At the same time, we found that service quality attributes such as crowding on board and comfort affect user choice, and particularly the attitude to use the minibus. Specifically, as we expected, an increase of the level of the minibus crowding causes a decrease of its utility, while an increase of the quality level of comfort on minibus increases the utility of this transport mode; specifically, this service aspect is very heterogeneously perceived among the users, as we can observe from the weight of the standard deviation. We can also observe that the weights linked to the travel time by walking or minibus are very similar; this result can be explained by observing the small difference between the average walking time and travel time by minibus.

\section{Conclusions}

The proposed study allowed the investigation about the factors affecting users' preferences between two alternative transport modes: walking and minibus. As we specified in the previous sections, the models proposed in this work concern a particular kind of choice, different from the other literature studies investigating the choice between sustainable (e.g., walking, bicycle, or public transport) and not sustainable transport modes (e.g., private car). In addition, we decided to investigate on two different kinds of factors potentially influencing this kind of choice, and specifically factors concerning the characteristics of the two transport modes, and attributes relating to personal attitudes of the users. The investigation on this particular kind of choice allowed to verify that the choice of walking is affected by personal attitude of the users, and to establish that the choice of a motorized mode like minibus is influenced by service quality attributes.

We underline that we propose the simulation of a choice between two transport modes which can be both considered as sustainable transport modes, and we believe that both options (walking and minibus) should be kept open for the users, rather than forcing them to make a choice. In this context we want to specify also that the aim of our research specifically focused on investigating the attitude of the users to walking or not. At this aim, we retain that this kind of investigation is easier if walking transport mode is compared to another sustainable transport mode available in the same path where users can walk, rather than different modes such as private car which imply the use of other paths. 
Concerning the specific case of the university campus described in this study, we can say that sustainable modes could be promoted by the improvement of the quality levels of public transport connecting the city and the hinterland with the campus; the increase of the use of public transport would conduct to an increase of both the sustainable modes investigated in this work. Also transport policies such as the introduction of car parking fares could be effective to reduce the use of the private car to reach the campus, and consequently increase the use of sustainable transport modes to move inside the campus (e.g. walking and electric minibus).

\section{References}

[1] N. Ziye, "The Analytical Tools For Pedestrian Mobility Design", Towards a Sustainable Campus Transportation, Master of Science Thesis, Milano, (2011).

[2] S. Bamberg, I. Ajzen and P. Schmidt, "Choice of travel mode in the theory of planned behavior: The roles of past behavior, habit, and reasoned action", Basic and applied social psych., vol. 25, no. 3, (2003), pp. 175-187.

[3] C. M. Collins and S. M. Chambers, "Psychological and situational influences on commuter-transport-mode choice", Environment and Behavior, vol. 37, no. 5, (2005), pp. 640-661.

[4] S. Kim, Y. J. Joo and S. H. Park, "Pedestrian Path Findings using Multi-Factors Affected Walking", Proceedings of the Geospatial World Forum, (2011) January 18-21; Hyderabad, India.

[5] S. Handy, "Methodology for Exploring the link between urban Form and Travel Behavior", Transportation Research Part D, vol. 1, no. 2, (1996), pp. 151-165.

[6] B. E.Saelens and S. Handy, "Built environment correlates of walking: a review", Medicine and science in sports and exercise, vol. 40, no. 7, (2008), pp. S550-S566.

[7] C. Lee and A. V. Mouden, "The 3Ds + R: Quantifying land use and urban form correlates of walking", Transportation Research Part D, vol. 11, (2006), pp. 204-215.

[8] M. Mahalawat and S. Rayan, "Examination of Student Travel Mode Choice", Proceedings of the 86th Annual Meeting of the Transportation Research Board, (2007) January, Washington DC, USA.

[9] R. Ewing, W. Schroeer and W. Greene, "School Location and Student Travel-Analysis of Factors Affecting Model Choice", Transportation Research Record: Journal of the Transportation Research Boar, vol. 1895, (2004), pp. 55-63.

[10] D. Parisi and B. Hondorp, "Transportation Professionals Get Involved with Safe Routes to School”, ITE journal, (2005) March, pp. 41-46.

[11] H. Zhou, J. Zhao, P. Hsu and J. Rouse, "Identifying Factors Affecting the Number of Students Walking or Biking to School”, ITE Journal, (2009) October, pp. 40-44.

[12] C. Cirillo, L. Eboli and G. Mazzulla, "On the asymmetric user perception of transit service quality", International Journal of Sustainable Transportation, vol. 5, (2011), pp. 216-32.

[13] L. dell'Olio, A. Ibeas and P. Cecín, "Modelling user perception of bus transit quality", Transport Policy, vol. 17, no. 6, (2010), pp. 388-397.

[14] J. de Ona, R. de Ona and F. J. Calvo, "A classification tree approach to identify key factors of transit service quality”, Expert System with Applications, vol. 39, (2012), pp. 11164-11171.

[15] L. Eboli and G. Mazzulla, "A Stated Preference Experiment for Measuring Service Quality in Public Transport", Transportation Planning and Technology, vol. 3, no. 5, (2008), pp. 509-523.

[16] L. Eboli and G. Mazzulla, "How to capture the passengers' point of view on a transit service through rating and choice options", Transport Reviews, vol. 30, (2010), pp. 435-450.

[17] L. Eboli and G. Mazzulla, "A methodology for evaluating transit service quality based on subjective and objective measures from the passenger's point of view", Transport Policy, vol. 18, (2011), pp. 172-181.

[18] L. Eboli and G. Mazzulla, "Performance indicators for an objective measure of public transport service quality", European Transport, vol. 51, (2012), pp. 1-21.

[19] T. B. Joewono and H. Kubota, "User perception of private paratransit operation in Indonesia", Journal of Public Transportation, vol. 10, no. 4, (2007), pp. 99-118.

[20] K. M. Nurul-Habib, L. Kattan and T. Islaam, "Model of personal attitudes towards transit service quality", Journal of Advanced Transportation, vol. 45, (2011), pp. 271-285.

[21] A. Nuzzolo, D.C. Festa, D. Gattuso and S. Gori, (Eds,), "Sistemi di trasporto collettivo avanzati a media potenzialità: analisi funzionali ed economico-finanziarie", Laruffa editore S.r.l., Reggio Calabria, (2006).

[22] C. R. Bhat, "Random Utility-Based Discrete Choice Models for Travel Demand analysis, in Transportation systems planning”, Edited K. G. Goulias, CRC Press, Washington, D.C., (2003), pp. (10)1-(10)29.

[23] K. E. Train, "Discrete Choice Methods with Simulation”, Cambridge University Press, Cambridge, (2003).

[24] F. Bastin, C. Cirillo and P. L. Toint, "Application of an adaptive Monte Carlo algorithm to mixed logit estimation”, Trasportation Research Part B, vol. 40, (2006), pp. 577-593. 


\section{Authors}

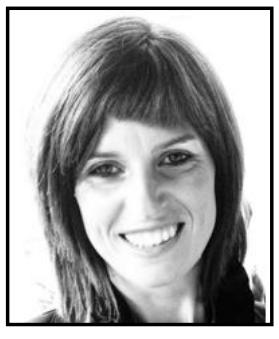

\section{Laura Eboli}

Ph.D. in "Environmental planning and technologies" in 2008 from the University of Calabria, Italy. She holds a master's degree in transport systems management from the University of Calabria. She graduated in Environmental Engineering in 2002 from University of Calabria.

Assistant Professor of "Management of the Transportation Systems". Since 2004 she has cooperated to the didactic and research activities in the Department of Land Use Planning of the University of Calabria. Today she is an affiliated member of the Department of Civil Engineering.

Author of about 60 papers, edited in Italian and international literature. Her publications have appeared in transportation journals, including the Transportation Planning and Technology, Journal of Public Transportation, European Transport, Transport Reviews, Transport Policy, International Journal of Sustainable Transportation.

Areas of research in the interest of Laura Eboli are about transportation demand and supply analysis, transit system with particular interest in the measure of service quality, analysis of interaction among land use, environment and transports, and road safety. The major part of the research has focused on transit service quality, which was also the subject of her $\mathrm{PhD}$ thesis.

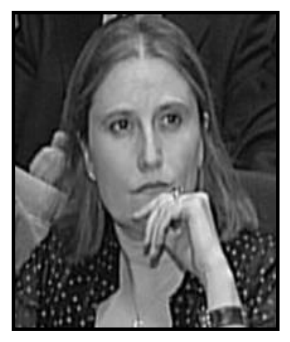

\section{Gabriella Mazzulla}

$\mathrm{Ph} . \mathrm{D}$. in "Road Infrastructure and Transportation System", achieved in 2002 from University "Federico II" of Naples, Italy. She graduated in Civil Engineering, with orientation in Transportation Engineering, in 1995 from Calabria University, Italy.

Assistant Professor of "Fundamental of Transportation" and "Transit Systems". From 1996 to 2010 she has cooperated to the didactic and research activities in the Department of Land Use Planning of the University of Calabria. Today she is an affiliated member of the Department of Civil Engineering.

Author of about 100 publications, edited in Italian and international literature. Her publications have appeared in transportation journals, including the Transportation Planning and Technology, Journal of Public Transportation, European Transport, European Journal of Operational Research, Transport Reviews, Transport Policy, International Journal of Sustainable Transportation, European Transport Research Review, Transportation Research Forum.

Her research interests focused on transportation planning, specifically analysis, modelling, and estimation of travel demand, design of transportation networks and simulation of traffic flow, and environmental impact appraisal of transportation facilities, with particular regard to 
atmospheric and noise pollution from road traffic. Currently, areas of research in the interest of Gabriella Mazzulla are about transit service quality measure and evaluation, analysis of interaction among land use and transport systems, and road accident risk analysis.

She contributed to some national and international researcher projects as coordinator or member of the working group.

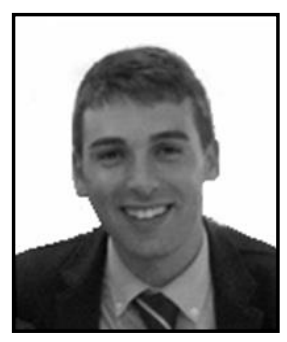

\section{Antonio Salandria}

$\mathrm{He}$ is attending a master in road safety by the title "Information systems and new technologies for the management of road safety" at the University of Calabria. He graduated in Civil Engineering with orientation in Transportation Engineering, in 2011 from University of Calabria. 